\title{
The Current Carriers' Dispersion Law of a Crystal, their Chemical Potential and a Set of Important Properties of Crystals
}

\author{
${ }^{1}$ Lviv Polytechnic National University, Lviv, Ukraine, jabudjak@ukr.net \\ ${ }^{2}$ Krakow Polytechnic, Krakow, Poland, tadeuszwaclawski00@gmail.com
}

\begin{abstract}
In this paper, a new non-parabolic dispersion law has been established, which for a small parameter of the spectrum nonparabolicity coincides with the known Kane's nonparabolic dispersion law. The Kane's dispersion law works well when the well-known parameter of nonparabolicity is much less than 1, and the new law works well enough when the parameter of nonparabolicity is less than 1. In addition, this law shows that crystals with a band gap (i.e., forbidden band width) $E_{G} \sim 10^{-1} \mathrm{eV}$ - these are semiconductor crystals, crystals with $E_{G} \sim 10^{-2} e V-$ these are metals.
\end{abstract}

Keywords: dispersion law, chemical potential, metals, semiconductor crystals.

Received 24 March 2020; Accepted 15 June 2020.

\section{General isotropic dispersion law}

In the papers [1-5], it was shown that in the isotropic crystals in a weak magnetic field or in the absence of this, all their thermal and kinetic properties are described by the computational functional $J\left(j, v, \mu^{\bullet}, T\right)$. This functional depends on the dispersion law $\varepsilon(\vec{p})$ and on the chemical potential $\mu$. For an arbitrary dispersion law and for arbitrary chemical potential this functional has the form:

$J(j, v, \mu, T)=\int_{0}^{\infty}\left(\frac{\varepsilon}{k T}\right)^{j} u(\varepsilon)^{v} G(\varepsilon)\left(-\frac{\partial f_{0}(\varepsilon, \mu)}{\partial \varepsilon}\right) d \varepsilon$,

where $u(\varepsilon)$ is the scattering function which determines the effect of the current carriers scattering processes by defects of crystal lattice on the crystal's kinetic properties, $g(\varepsilon)$ is the density of the energy levels of the current carriers in allowed energy bands, $G(\varepsilon)=$ $\int_{0}^{\varepsilon} g(\varepsilon) d \varepsilon, f_{0}(\varepsilon, \mu)$ is the generally known Fermi-Dirac function, the numerical indices $j, v$ can have the following values: $j=0,1,2 ; v=0,1,2$ and for the computations of thermal properties of charge carriers gas the index $v \equiv 0$.

Quantum mechanical calculations of the kinetic and thermal properties of the isotropic crystals established the following general isotropic dispersion law:

$$
\frac{p^{2}}{2 m m_{n}}=E(\varepsilon)
$$

where $E(\varepsilon)$ is the homogeneous quantum mechanical function of the energy of a charge carrier with the reduced effective mass $m_{n}, m$ is the electron mass.

\section{Allowed values of $\beta, \mu, \mu_{0}$ and $E_{G}$ in the integral $I\left(j, v, \mu^{\bullet}, T\right)$ in normal temperature conditions of observation}

The computational functional $J(j, v, \mu, T)$ for the dispersion law (2) has the following form:

$J(j, v, \mu, T)=U(r, T)^{v} N_{C}(T) I\left(j, v, \mu^{\bullet}, T\right)$.

This formula uses the following notations:

$N_{C}(T)=\frac{8}{3 \sqrt{\pi}}\left(\frac{2 m m_{n} k T}{h^{2}}\right)^{3 / 2}$,

$U(r, T)$ is the dimensional temperature function, it has the dimension of mobility and it is described by this formula: 


$$
U(r, T)=\left[\frac{1}{T}\left(U_{A} \delta(0, r)+U_{O} \delta(1, r)+U_{I} \delta(2, r)\right)\right](m)_{n}^{(r-5 / 2)} T^{(r-1 / 2)}
$$

where $U_{A}, U_{O}, U_{I}$ are the crystal dimensional constants, which depend on the nature of the semiconductor crystal and the scattering mechanisms of current carriers by the crystal lattice defects, these mechanisms (modes) are characterized by the scattering parameter $r, \delta(m, n)$ it is the known Kronecker symbol, it has the following values: $\delta(m, n)=1$ for $m=n, \delta(m, n)=0$ for $m \neq n$, the dimensionless functional $I\left(j, v, \mu^{\bullet}, T\right)$ takes the form: $I\left(j, v, \mu^{\bullet}, T\right)=\int_{0}^{\infty} x^{j} \frac{E(x)^{(r v-v / 2+3 / 2)}}{\left(\frac{d E(x)}{d x}\right)^{2 v}}\left(-\frac{d f_{0}}{d x}\right) d x$.
In crystals with narrow energy gaps $E_{G}$, the Kane's dispersion law is often observed:

$$
\frac{p^{2}}{2 m m_{n}}=E(\varepsilon)=\left(\varepsilon+\frac{\varepsilon^{2}}{E_{G}}\right)=\left(\varepsilon+\beta(T) \frac{\varepsilon^{2}}{k T}\right),
$$

- this law has also been calculated in the cited work [1].

For this dispersion law, $\beta(T)=\frac{k T}{E_{G}}$ is the parameter of nonparabolicity and the dimensionless functional $I\left(j, v, \mu^{\bullet}, T\right)(5)$ is given as:

$$
I\left(j, v, \mu^{\bullet}, \beta(T)\right)=\int_{0}^{\infty} x^{j} \frac{\left(x+\beta(T) x^{2}\right)^{(r v-v / 2+3 / 2)}}{(1+2 \beta(T) x)^{2 v}}\left(-\frac{d f_{0}}{d x}\right) d x
$$

Analysis of the functional computations of the cited works [1-5] shows that the quantum mechanical function $E(\varepsilon)$ in the dispersion relation (2) for crystals with small energy gaps has the following form:

$E(\varepsilon)=\varepsilon\left(1+\frac{\varepsilon}{E_{G}}\right)=\varepsilon\left(1+\beta(T) \frac{\varepsilon}{k T}\right) \approx \varepsilon \exp \left(\frac{\varepsilon}{E_{G}}\right)$, and the computational functional $J\left(j, v, r, \mu^{\bullet}, T\right)$ for the dispersion law (8) is equal to:

$J\left(j, v, r, \mu^{\bullet}, T\right)=U(r, T)^{v} N_{C}(T) I\left(j, v, r, \mu^{\bullet}, T\right)$, where

$$
\begin{gathered}
I\left(j, v, r, \mu^{\bullet}, T\right)=\int_{0}^{\infty} x^{(a(r, v)+j)} \cdot \exp \left(-\beta(T) \cdot(4 \cdot v-a(r, v) \cdot x) \cdot\left(-\frac{d}{d x} f_{0}\left(x, \mu^{\bullet}\right)\right) d x,\right. \\
a(r, v)=r \cdot v-v / 2+3 / 2 .
\end{gathered}
$$

It can be easily shown that the integral (10) is divergent if the parameter of nonparabolicity fulfils the condition:

$$
\beta(T) \cdot(a(r, v)-4 \cdot v)=(a(r, v)-4 \cdot v) \cdot\left(\frac{k v}{E_{G}}\right) \cdot T=(a(r, v)-4 \cdot v) \cdot \frac{8.614 \cdot 10^{-5}}{E_{G}} \cdot T=1
$$

Indeed, under this condition, the integral (10) has the following value:

$$
\begin{gathered}
I\left(j, v, r, \mu^{\bullet}, T\right)=\int_{0}^{\infty} x^{(a(r, v)+j)} \cdot \exp (\beta(T) \cdot(a(r, v)-4 \cdot v) \cdot x) \cdot\left(-\frac{d}{d x} f_{0}\left(x, \mu^{\bullet}\right)\right) d x= \\
=\int_{0}^{\infty} x^{(3 / 2+j)} \cdot \exp (x) \cdot\left(-\frac{d}{d x} f_{0}\left(x, \mu^{\bullet}\right)\right) d x \rightarrow \infty
\end{gathered}
$$

In order to avoid this divergence, the parameter $\beta(T)$ should fulfil this condition: $\beta(T) \cdot(a(r, v)-4 \cdot v)<1$, that is, $\beta(T)<(a(r, v)-4 \cdot v)^{-1}$, then the parameter $\beta(T)$ must be within the following interval of values:

$$
0<\beta(T)<(a(r, v)-4 \cdot v)^{-1} \text {. }
$$

For the index $v=0$ which occurs in the computational functionals of different crystal properties, the above condition is described by the following formula:

$$
0<\beta(T)<2 / 3 \text {. }
$$

Let us consider the dimensionless integral (10) for a crystal with non-degenerate current carriers. In this case, this integral is convergent and it has the following value:

$$
I(j, v, r, T)=\int_{0}^{\infty} x^{(a(r, v)+j)} \cdot \exp (-x(1+\beta(T) \cdot(4 \cdot v-a(r, v))) d x \cdot \exp (\mu)=F(j, v, r, T) \cdot \exp (\mu)
$$

where: $F(j, v, r, T)=\Gamma(a(r, v)+j+1) \cdot(1+\beta(T) \cdot(4 \cdot v-a(r, v)))^{-(a(r, v)+j+1)}$.

In this formula, the parameter $\mu^{\bullet}$ is the reduced chemical potential $\frac{\mu}{\mathrm{kV} \cdot \mathrm{T}}$, and the functional $F(j, v, r, T)$ under condition that $j=0, v=0$, is equal to:

$$
F(0,0, r, T)=\Gamma(5 / 2) \cdot\left(1-\frac{1.292 \cdot 10^{-4}}{E_{G}} \cdot T\right)^{-5 / 2}
$$

In what follows we give the values of the functional
(12) vs. temperature for two values of the energy gap width $E_{g} 1=10^{-2} \mathrm{eV}$ and $E_{g} 2=10^{-1} \mathrm{eV}$.

The experimental computer calculations of the functional (12) - these are described below - show that in the case of crystals with the energy gap $E_{g} 1=$ $10^{-2} \mathrm{eV}$, the values of this functional are non-adequate, 
because they have imaginary values.

$$
\begin{aligned}
& \mathrm{L}^{\langle 0\rangle}:=\mathrm{T} \quad \mathrm{L}^{\langle 1\rangle}:=\mathrm{F} 1 \quad \mathrm{~L}\langle 2\rangle \quad:=\mathrm{F} 2 \\
& \mathrm{~L}=\left(\begin{array}{ccc}
100 & -28.852 \mathrm{i} & 1.879 \\
150 & -1.56 \mathrm{i} & 2.278 \\
200 & -0.421 \mathrm{i} & 2.807 \\
250 & -0.179 \mathrm{i} & 3.525 \\
300 & -0.095 \mathrm{i} & 4.529 \\
350 & -0.057 \mathrm{i} & 5.985 \\
400 & -0.037 \mathrm{i} & 8.191
\end{array}\right) \quad \mathrm{F} 1=\mathrm{F}\left(10^{-2}, \mathrm{~T}\right)=\Gamma\left(\frac{5}{2}\right) \cdot\left(1-1.292 \cdot 10^{-2} \cdot \mathrm{T}\right)^{-\left(\frac{5}{2}\right)} \quad \quad \mathrm{F} 2=\mathrm{F}\left(10^{-1}, \mathrm{~T}\right)=\Gamma\left(\frac{5}{2}\right) \cdot\left(1-1.292 \cdot 10^{-3} \cdot \mathrm{T}_{\mathrm{i}}\right)^{-\left(\frac{5}{2}\right)}
\end{aligned}
$$

Scheme 1. The diagram of computer calculations of functional (12).

It should be emphasized that the functional (12) determines the current carriers concentration in a crystal as well as several its important properties and this functional occurs in the neutrality equations. In this regard, these results of calculations of this functional seem to deny the existence of crystals with the energy gap width $E_{g} 1=10^{-2} \mathrm{eV}$, since for the normal temperature conditions of observations, when the temperature of the crystal $T \approx 10^{2} \mathrm{~K}$, this functional has an imaginary values. But in the low temperature interval, when the temperature of the crystal $T \approx 10^{1} \mathrm{~K}$, the values of the functional become real.

Crystals with the energy gap width $E_{g} 1 \approx 10^{-2} \mathrm{eV}$ may exist, but they must be classified as metals, in which the concentration of current carriers does not depend on temperature and it equals $n \approx 10^{22} \mathrm{~cm}-3$. These crystals are strongly (highly) degenerate, that is their reduced chemical potential $\mu^{\bullet}>=4$.

This concentration according to the Sommerfeld approximation is described by the following formula:

$$
\begin{gathered}
n=N_{C}(T) \cdot I(0,0, r, \mu, T)=N_{C}(T) \cdot \int_{0}^{\infty} x^{(a(r, 0))} \cdot \exp (\beta(T) \cdot a(r, 0) \cdot x) \cdot\left(-\frac{d}{d x} f_{0}\left(x, \mu^{\bullet}\right)\right) d x= \\
=N_{C}(T) \cdot \int_{0}^{\infty} x^{\frac{3}{2}} \cdot \exp \left(\beta(T) \cdot \frac{3}{2} \cdot x\right) \cdot\left(-\frac{d}{d x} f_{0}\left(x, \mu^{\bullet}\right)\right) d x= \\
=G\left(\mu_{0}\right)+\left(\mu-\mu_{0}\right) \cdot \frac{d G\left(\mu_{0}\right)}{d \mu_{0}}+\frac{\pi^{2}}{6} \cdot(k T)^{2} \cdot \frac{d^{2} G\left(\mu_{0}\right)}{d^{2} \mu_{0}} .
\end{gathered}
$$

In this equation, $G\left(\mu_{0}\right)=\frac{8}{3 \sqrt{\pi}}\left(\frac{2 \pi m m_{n} k}{h^{2} k v}\right)^{3 / 2}$. $\mu_{0}^{3 / 2} \exp \left(3 / 2 \cdot \frac{\mu_{0}}{E_{G}}\right), \mu_{0}=\mu^{\bullet} \cdot k V \cdot T$, and $\mu_{0}$ is the wellknown Fermi level. This equation is called the neutrality equation for crystals with highly degenerate current carriers. It falls into two parts.

One of these parts has no explicit dependence on temperature:

$$
n=G\left(\mu_{0}\right) \text {, that is } 1=\frac{G\left(\mu_{0}\right)}{n},
$$

and with the use the formula (14), it is possible to calculate the Fermi level $\mu_{0}$.

The second part of the neutrality equation (13) has a temperature dependence:

$$
\left(\mu-\mu_{0}\right) \cdot \frac{d G\left(\mu_{0}\right)}{d \mu_{0}}+\frac{\pi^{2}}{6} \cdot(k T)^{2} \cdot \frac{d^{2} G\left(\mu_{0}\right)}{d^{2} \mu_{0}}=0,
$$

with which we can easily determine the chemical potential of degenerate current carriers:

$$
\mu=\mu_{0}\left(1-\frac{\pi^{2}}{6} \cdot \frac{1}{\frac{d G\left(\mu_{0}\right)}{d \mu_{0}}} \cdot(k T)^{2} \cdot \frac{d^{2} G\left(\mu_{0}\right)}{d^{2} \mu_{0}}\right)
$$

or

$$
\mu^{\bullet}=\mu_{0}^{\bullet}\left(1-\frac{\pi^{2}}{6} \cdot \frac{1}{\frac{d G\left(\mu_{0}^{\bullet}\right)}{d \mu \bullet 0}} \cdot(k T)^{2} \cdot \frac{d^{2} G\left(\mu_{0}^{\bullet}\right)}{d^{2} \mu_{0}^{\bullet}}\right)
$$

In the formula (17), the reduced quantities $\mu^{\bullet}=\frac{\mu}{k V \cdot T}$; $\mu_{0}^{\bullet}=\frac{\mu_{0}}{k V \cdot T}$ are denoted by dots.

The Fermi level $\mu_{0}$ which is in the formulas (16) and (17) should be calculated with the use of the formula (14):

$$
1=\frac{G\left(\mu_{0}\right)}{n}=\frac{1}{n} \cdot \frac{8}{3 \sqrt{\pi}}\left(\frac{2 \pi m m_{n} k}{h^{2} k v}\right)^{3 / 2} \cdot \mu_{0}^{3 / 2} \exp \left(3 / 2 \cdot \frac{\mu_{0}}{E_{G}}\right)=\frac{4.543 \cdot 10^{21} \cdot m n^{3 / 2}}{n} \cdot \mu_{0}^{3 / 2} \exp \left(3 / 2 \cdot \frac{\mu_{0}}{E_{G}}\right),
$$


and it leads to the following equation:

$$
1=\left(\frac{4.543 \cdot 10^{21}}{n}\right)^{2 / 3} \cdot m n \cdot \mu_{0} \exp \left(\frac{\mu_{0}}{E_{G}}\right)=\left(\frac{4.543 \cdot 10^{21}}{n}\right)^{2 / 3} \cdot m n \cdot E_{G} \cdot z \exp (z) .
$$

This equation has an adequate solution only if the Fermi level $\mu_{0} \mathrm{eV}$ fulfils the condition $\frac{\mu_{0}}{E_{G}}=z<1$, and its approximate root has this value:

$$
z=\frac{\mu_{0}}{E_{G}} \approx 10^{-1} \text {, that is } \mu_{0} \approx 10^{-1} \cdot E_{G} .
$$

It was previously proved that the nonparabolicity parameter should meet this condition:

$$
1.5 \cdot \beta(T)=1.5 \cdot \frac{\mathrm{kV} \cdot T}{E_{G}}=1.5 \cdot \frac{\mu_{0}}{E_{G}}=\frac{1.292 \cdot 10^{-2}}{E_{G}} \cdot\left(\frac{T}{10^{2}}\right)<1 \text {. }
$$

Now we consider this inequality under normal temperature conditions of observation, when the crystal's temperature becomes $T \approx 10^{2} \mathrm{~K}$.

For crystals with with a narrow energy gap $E_{G} \approx$ $10^{-2} \mathrm{eV}$, the condition (20) is written as follows:

$$
1.292 \cdot\left(\frac{T}{10^{2}}\right)<1 \text {, }
$$

and this means that calculations of the properties of such crystals will be adequate at a low temperature of observation in degrees Kelvin $\left(\frac{T}{10^{2}}\right) \approx<1 \mathrm{~K}$. This is an area of low temperatures, and crystals with this characteristic belong to the class of metals.

For crystals with energy gap $E_{G} \approx 10^{-1} \mathrm{eV}$, the condition (20) is written as follows:

$$
1.292 \cdot\left(\frac{T}{10^{3}}\right)<1 .
$$

This condition for such crystals ensures the adequacy of calculations of their thermal and kinetic properties over the entire normal temperature interval.

Calculations given here show that crystals with the energy gap $E_{G} \approx 10^{-1} \mathrm{eV}$ belong to typical semiconductor crystals, and crystals with $E_{G} \approx 10^{-2} \mathrm{eV}$ belong to metal crystals.

Budzhak Ya.S. - Professor, Doctor of Science; Waclawski T. - Adjunct, Doctor of Philosophy in Physics.

[1] Ja.S. Budjak, Physics and Chemistry of Solid State 18(1), 7, (2017) (doi: 10.15330/pcss.18.1.7-14).

[2] Ya.S. Budzhak, T. Wacławski, Physics and Chemistry of Solid State 19(2), 134, (2018) (doi: 10.15330/pcss.19.2.134-138).

[3] Ya. S. Budzhak, T. Wacławski, Physics and Chemistry of Solid State 19(4), 303, (2018) (doi: 10.15330/pcss.19.4.303-306).

[4] Ya.S. Budzhak, L.O. Vasilechko, Foundations of statistical theory of thermal and kinetic properties of semiconductor crystals (Liga-Pres, Lviv, 2016).

[5] Ya.S. Budzhak, A.O. Druzhinin, T. Wacławski, Modern Statistical Methods of Investigations of Properties of Crystals as Micro- and Nanoelectronics Materials (PublishingHouse of Lviv Polytechnic, Lviv, 2018).

[6] Ya.S. Budzhak, Technical News 49(1), 12, (2019).

[7] A.G. Samoilovich, Thermodynamics and Statistical Physics (State Publishing House of Technical and Theoretical Literature, Moscow, 1955).

\title{
Я.С. Буджак ${ }^{1}$, Т. Вацлавський ${ }^{2}$
}

\section{Закон дисперсії носіїв струму кристала, їх хімічний потенціал і множина важливих властивостей кристалів}

\author{
${ }^{1}$ Національний університет «Львівська політехніка», м. Львів, Україна, jabudjak@ukr.net \\ ${ }^{2}$ Краківська політехніка, м. Краків, Польща, tadeuszwaclawski00@ gmail.com
}

\begin{abstract}
В даній роботі обгрунтований новий непараболічний закон дисперсії, який при малому параметрі непараболічності спектра співпадає з відомимнепараболічним законом дисперсії Кейна. Закон дисперсії Кейна добре працює коли загальновідомий параметр непараболічності багато менший від одиниці, а новий закон досить добре працює при параметрі непараболічності меншшим від одиниці. Крім цього цей закон показує що кристали $з$ шириною забороненої зони $E_{G} \sim 10^{-1} \mathrm{eV}$ - це напівпровідникові кристали, кристали з $E_{G} \sim 10^{-2} \mathrm{eV}$ - це метали.
\end{abstract}

Ключові слова: закон дисперсії, хімічний потенціал, метали, напівпровідникові кристали. 